\title{
AS CRIANÇAS E SEUS TANTOS MODOS DE SER E ESTAR NO MUNDO: DESAFIOS QUE ENVOLVEM A PRODUÇÃO DE REGISTROS DE DESENVOLVIMENTO NA EDUCAÇÃO INFANTIL
}

\author{
Heloisa Josiele Santos Carreiro ${ }^{\mathrm{i}}$
}

\begin{abstract}
Resumo: O artigo ancora suas reflexões a partir do processo de produção de relatórios de desenvolvimento bimestrais das crianças, que eram produzidos pelas educadoras do Centro de Educação Infantil Carolina Amorim, pensando divergências de leituras sobre o próprio ser criança. Nossa metodologia centra-se nos estudos cotidianos, onde os profissionais da instituição investigam a própria prática. Para pensar as questões da avaliação da aprendizagem, nosso diálogo se estreita com os estudos de autores que questionam o silenciamento de saberes dos sujeitos envolvidos neste processo, no modo como produzimos os instrumentos de registro da avaliação escolar. Assim, o artigo parte da complexidade que envolve pensar um registro do desenvolvimento infantil a quatro mãos.
\end{abstract}

Palavras-Chave: Educação Infantil; Processos Formativos; Registros de Avaliação.

\section{CHILDREN AND THEIR MANY WAYS OF BEING IN THE WORLD: CHALLENGES IN THE PRODUCTION OF DEVELOPMENT REGISTERS IN THE EARLY CHILDHOOD EDUCATION}

\begin{abstract}
The article reflects from bimonthly report development of production process of children, which were produced by the educators in Early Childhood Education Center Carolina Amorim, thinking readings disagreements about being a child himself. Our methodology focuses on the daily studies, where professionals of the institution investigate the practice itself. To think the issues of assessment of learning, our dialogue narrows with authors that studies questions the silencing of knowledge of the subjects involved in this process, in the way we produce the school assessment recording instruments. Thus, Article of the complexity that involves thinking a record of child development four hands.
\end{abstract}

Key Words: Early Childhood Education; Formative Processes; Evaluation Records.

\section{Introdução}

Este texto trabalha com um recorte de uma pesquisa-ação realizada ao longo da produção da minha tese de doutoramento: Rotinas arquitetadas e cotidianos - vividos tensões e possibilidades na educação infantil (CARREIRO, 2013). A tese foi desenvolvida no Centro de Educação Infantil (CEI) Carolina Amorim da rede Municipal de Educação de Petrópolis, região serrana do estado do Rio de Janeiro, no período entre 2009 e 2012. 
A tese propunha uma discussão sobre o processo de reflexão das rotinas propostas pelos profissionais da instituição às crianças que ali encontravam-se matriculadas; o trabalho era composto com os seguintes caminhos teóricos-metodológicos: a) o paradigma indiciário de Ginzburg (1989); b) os estudos com o cotidiano (GARCIA; ALVES, 2000) e, os princípios teóricos que norteiam os estudos no campo da sociologia da infância (CORSARO, 2011; SARMENTO, 2008; FERREIRA, 2004; QVORTRUP, 2011). A principal estratégia metodológica da tese foi utilizar-se das falas das crianças como principal fio condutor para provocação das reflexões formativas tecidas no interior da instituição.

Assim, este artigo apresenta uma experiência formativa que não compôs o texto final da tese, uma vez que o que foi recortado em seu processo interpretativo tinha como foco, elementos mais específicos da rotina, tendo a voz da criança como principal protagonista. Contudo, a discussão que trago é parte do material de campo da tese, sua incorporação a este material se deu, porque a discussão desencadeada nos convocou a refletir de forma empírica e teoricamente sobre as concepções de criança e infância com que trabalhávamos na instituição. Uma questão central em qualquer trabalho dos estudos cotidianos com a pequena infância: entender quais as concepções, da tão referida, infância dialogam e/ou entram em tensão no trabalho pedagógico que desenvolvemos na Educação Infantil.

Neste artigo teceremos nossa reflexão, a partir do processo de produção de relatórios de desenvolvimento bimestrais das crianças, que eram produzidos pelas educadoras do CEI Carolina Amorim, pensando divergências de leituras sobre o próprio ser criança. Assim, o artigo parte da complexidade que envolve pensar um registro do desenvolvimento infantil a quatro mãos. Em algum momento, para a equipe de profissionais daquela Instituição esta questão representou um desafio pelas seguintes indagações: a) será que dois pares de olhos enxergam as mesmas coisas sobre uma mesma criança? E tem que enxergar as mesmas coisas? Quais diferenças podem haver entre um olhar e outro? b) Como as experiências interativas produzidas entre criança-adulto-criança afetam nos modos como os adultos compreendem o desenvolvimento infantil? c) Como pensar um registro de desenvolvimento infantil que traga diferentes leituras dos adultos sobre uma mesma criança? d) Como construir um registro de desenvolvimento infantil que albergue as múltiplas possibilidades de ser e estar no mundo experienciadas pelas crianças? Ou mesmo que trabalhe com as diferenças nas formas como os adultos as enxergam? 
Estas foram questões que nos deparamos quando as educadoras Letícia e Celeste, do Agrupamento do Segundo Período, revelaram discordância sobre Edson André, um menino de dois anos.

\section{Quando as educadoras não vêm o mesmo menino: quando uma turma tem dois "Andrés", mesmo fisicamente tendo um só}

Para adentrar um pouco mais na questão trazemos o seguinte contexto: é final de bimestre e as educadoras encontram-se eufórica ao fechamento dos chamados relatórios, que devem apresentar um pouco do desenvolvimento de cada criança. Na última reunião pedagógica o grupo construiu junto com a gestão algumas lentes ${ }^{\mathrm{ii}}$ possíveis para encaminharmos o texto final do relatório, apesar de cada educador ter a liberdade de trazer os elementos que achar mais relevantes sobre o processo de desenvolvimento das crianças com as quais atuam.

Quase sempre as educadoras dialogavam com as lentes e raramente traziam elementos próprios em relação a percepção sobre o desenvolvimento infantil. Em todo período que trabalhei na instituição nenhuma dupla de educadoras fez uma abordagem totalmente nova às lentes que ajudam o olhar, a recortar as observações. Minha suposição em relação ao não abandono das lentes, chaves de leituras, pelos profissionais, encontra-se no fato de questões relativas a insegurança pedagógica das educadoras.

A questão complicada é que a rede municipal de educação de Petrópolis, não exige via edital de concurso, a formação pedagógica destes profissionais (educadores de creche), pois a previsão é que atuariam sempre com a supervisão de um professor. O que na prática não acontece e muitos deles assumem em dupla a responsabilidade pelas dimensões do educar e cuidar das crianças matriculadas no centro de Educação Infantil, contando como apoio pedagógico, a gestão da unidade infantil.

Neste contexto as educadoras, Leticia e Celeste abordaram a gestão pedagógica sobre impasses em relação a produção do relatório de desenvolvimento de Edson André, uma vez que não compartilhavam da mesma percepção sobre o desenvolvimento do menino.

As educadoras no processo de elaboração da escrita dos relatórios adotavam algumas estratégias para o encaminhamento do exercício das lentes, que as ajudavam a produzi-lo: algumas sentavam juntas e realizavam a construção do texto e, outras dividiam as crianças em 
dois grupos, articulavam a construção do texto e compartilhavam a versão final fechando as pequenas divergências. Em ambos os casos a versão definitiva que era encaminhada às famílias das crianças era feita em parceria com a gestão.

Este encaminhamento era adotado pela ausência de professor regente nas turmas de Educação Infantil, das instituições que funcionam em período integral. Na ausência do professor, que seria o profissional responsável pela elaboração destes relatórios e na impossibilidade da gestão conseguir encaminhar um relatório que trouxesse elementos significativos do desenvolvimento de todas as crianças da instituição. Os profissionais do CEI Carolina Amorim instituíram este caminho metodológico na produção do relatório de desenvolvimento das crianças ${ }^{\mathrm{iii}}$.

O encaminhamento metodológico adotado pela instituição para produção dos relatórios, nunca pensou que pudesse um dia enfrentar grandes divergências de leituras dos profissionais sobre as crianças, pois quase sempre conseguia fechar as pequenas divergências. Ora suprimindo informações, ora aprofundando o olhar e o diálogo com as crianças e, com os demais profissionais da instituição, como se tirássemos uma "prova dos nove". Contudo, chegou um dia em que não houve supressão possível. Pois, os olhos interpretativos e as experiências de educar e cuidar de Letícia levantaram o seguinte argumento:

Olha vai ser impossível ajustar o registro escrito, encaminhado pela Celeste sobre André, pois eu discordo do modo como ela descreveu o Andrezinho. Ele não é aquele menino do relatório dela. Eu não assino naquilo. Já falei com ela, mas ela disse que ela vê ele daquele jeito... Ô Helô vê o que você faz. Aquele registro, como está, eu não assino.

Pega de surpresa por Letícia, pedi um tempo para pensar. Pois ainda não tinha lido o registro e nem conversado com Celeste em relação aos encaminhamentos feitos por ela. E no dia seguinte propus a Letícia que fizesse o seu registro sobre o André. Pois seria legal compartilhar com o grupo de profissionais do CEI e até com as famílias das crianças, os olhares divergentes que temos em relação as crianças e que seria bom refletirmos sobre a seguinte questão: onde o nosso olhar se alimenta para ver/ entender as crianças? Mesmo dizendo achar a proposta uma loucura Letícia topou fazer. Apesar de questionar-se sobre qual o sentido de ter relatórios diferentes. Eu disse que aquela era a primeira vez que enfrentávamos aquele problema. 
Contudo, defendi que essa divergência seria uma forma interessante para refletirmos coletivamente, sobre os muitos modos possíveis de ser criança e a complexidade que envolve a captura destes modos de ser, por escrito. E os registros produzidos pelas educadoras nos apresentaram os seguintes 'Andrés'.

Segue abaixo um pequeno fragmento do registro e suas diferenças para percebermos as leituras diferenciadas entre as duas educadoras:

\begin{tabular}{|c|c|}
\hline O André Interpretado por Letícia & O André interpretado por Celeste \\
\hline $\begin{array}{l}\text {.. Durante este período percebi que a } \\
\text { interação com os colegas não tem sido } \\
\text { desenvolvida com muitos conflitos, uma vez } \\
\text { que compartilha os brinquedos com os } \\
\text { amigos, sabe esperar calmamente pela sua } \\
\text { vez de fazer a atividade. Constantemente, ao } \\
\text { entrar em conflito pede o auxílio dos adultos } \\
\text { a sua volta para resolver, utilizando-se da } \\
\text { linguagem gestual e/ou de balbucios. Por } \\
\text { vezes, suas interações com os colegas } \\
\text { envolvem empurrões e mordidas, nem } \\
\text { sempre consigo perceber o início dos } \\
\text { conflitos, mas os colegas às vezes o apontam } \\
\text { como o disparador de alguns. Em relação os } \\
\text { conflitos que percebi quase sempre a causa é } \\
\text { disputa por brinquedos. } \\
\text {... } \\
\text { Na interação com os adultos da instituição } \\
\text { Edson André revela-se carinhoso e responde } \\
\text { imediatamente as solicitações que lhes } \\
\text { fazemos, adora participar das atividades de } \\
\text { rotina do CEI, esteve aparentemente sempre } \\
\text { disposto a colaborar com a organização da } \\
\text { sala e a realizar as atividades que lhe } \\
\text { propomos. Adora as visitas de limpeza do tio } \\
\text { Sebastião e do tio Zé, sempre que eles entram } \\
\text { na sala, ele corre para pegar a pá de lixo. } \\
\text { Também, sente-se à vontade com tia Ana da } \\
\text { cozinha e gosta de ajudar a entregar as } \\
\text { mamadeiras. Tem muita afinidade e carinho } \\
\text { com as tias da sala e disputa com os amigos o } \\
\text { direito por ficar um pouquinho em nosso } \\
\text { colo. }\end{array}$ & $\begin{array}{l}\text {.. Durante este período percebi que a } \\
\text { interação com os colegas não tem sido } \\
\text { desenvolvida com muitos conflitos, pois } \\
\text { quase não percebo sua interação com os } \\
\text { demais amiguinhos, mantém-se isolado. } \\
\text { Quando, raramente, envolve-se em algum } \\
\text { conflito, não pede o auxílio dos adultos a sua } \\
\text { volta para resolver, costuma chorar e isola-se } \\
\text { ainda mais dos colegas e dos adultos a sua } \\
\text { volta. Não reage em situações de conflito } \\
\text { com os demais colegas recebendo mordidas e } \\
\text { empurrões. Os colegas constantemente } \\
\text { tomam seus brinquedos e sua reação é o } \\
\text { choro. } \\
\text {... } \\
\text { Na interação com os adultos da instituição } \\
\text { Edson André não se entrega facilmente, } \\
\text { parece estar sempre desconfiado e não parece } \\
\text { gostar das atividades de rotina fora da sala de } \\
\text { atividade. Eu o percebo inseguro, pois } \\
\text { quando vamos brincar na varanda ou no } \\
\text { refeitório, ou quando vamos lanchar, ele } \\
\text { sempre está a nossa procura com os olhos. E, } \\
\text { às vezes prefere ficar ao nosso lado, do que } \\
\text { interagir com os colegas. Ele atende de forma } \\
\text { imediata as solicitações que lhes fazemos, } \\
\text { mas com os demais profissionais da } \\
\text { instituição, não parece ficar à vontade. Mas é } \\
\text { dengoso e adora o nosso colinho na sala. }\end{array}$ \\
\hline & \\
\hline
\end{tabular}


Nossa reflexão cotidiana foi fortalecida pelos estudos de avaliação da aprendizagem de Esteban (2000), que em seus estudos traz a compreensão da escola como um lugar caracterizado pela multiplicidade de sujeitos e de experiências.

Contudo, esta pluralidade de sujeitos, vozes e experiências não aparecem na avaliação escolar. Os estudos de Esteban apontam que a avaliação escolar, nesta perspectiva excludente, silencia as pessoas, suas culturas e seus processos de construção de conhecimento (2000, p. 15). Neste artigo nos desafiamos a pensar como trazer a pluralidade de vozes das crianças e suas experiências conosco na rotina. Investigando nossa própria prática na instituição, buscamos refletir sobre como de modo polifônico os saberes dos profissionais poderiam se fazer presentes no relatório de desenvolvimento infantil, pois como Esteban (2000) reconhecemos que os caminhos da seleção, da classificação e da hierarquização de saberes e de pessoas, dificultam a expressão dos múltiplos saberes, negando a diversidade e contribuindo para o silenciamento dos alunos e alunas - e por que não, de professores e professoras (2000, p. 15) como se anuncia na tensão vivenciada por Letícia e Celeste, em relação aos saberes que assumem possuir sobre o menino, Edson André.

\section{Quando não cabe no papel os muitos modos de ser de uma criança}

Os relatórios produzidos pelas educadoras provocaram em um primeiro momento, nos profissionais da instituição, uma discussão sobre qual seria o verdadeiro em termos de se aproximar sobre quem André seria de fato na vida cotidiana. Contudo, provoquei ao grupo a pensar sobre a complexa experiência humana de estar no mundo, através da seguinte questão: somos sempre os mesmos em todos os lugares com as mesmas pessoas?

A discussão foi tensa, pois diferentes grupos de educadoras apresentavam os seguintes argumentos: a) acreditavam que éramos sempre os mesmos em todos os lugares, pois havia implicações morais na forma como nos apresentamos socialmente e apresentavam a compreensão de que ser diferente em diferentes lugares poderia expressar problemas morais, desvios de personalidade. O que seria compreendido como anormalidade. (Ponto de vista levantado pelas educadoras: Claudia Santos, Claudia Silva, Guilhermina, Andréa e Celeste); b) outro grupo pensava e defendia, exatamente, o oposto a partir do mesmo argumento: somos obrigados a ser diferentes nos contextos que circulamos, porque eles esperam de nós 
comportamentos morais diferentes. Então, era uma questão de aprender como se podia ser em cada lugar. (Ponto de vista levantado pelas educadoras: Márcia Brick, Ana, Silvana, Letícia e Cristina Constâncio) e; c) ainda tiveram educadoras que defendiam que nós humanos somos diferentes, não somente pelas relações morais implicadas nos contextos. Mas, sobretudo pelas questões afetivas que estavam envolvidas nas interações ali tecidas. Assim, não haveria um padrão de relação, mas experimentações de relações que se constroem cotidianamente, e que fazem com que nós humanos nos comportemos de forma tão diversa com diferentes sujeitos, parecendo em alguns momentos que somos um outro ser (Ponto de vista levantado pelas educadoras: Vanessa Fernandes e Mônique).

A discussão surgida na reunião de formação interna dos profissionais, nasce com o movimento de procura de uma verdade absoluta. Logo, o ponto de partida foi pensar qual relatório haveria de ser verdadeiro: o de Letícia ou o de Celeste? Pois, existe um fio condutor na forma de compreender a avaliação do desenvolvimento nas instituições escolares, que se assenta na perspectiva equivocada de construção de uma história única (ADICHIE, 2009). Trata-se de uma escrita linear que não apresente e/ou trabalhe com a presença das contradições. Movimento que nós mesmos fazíamos no processo de produção de nossos relatórios, quando as contradições apareciam ou as suprimíamos ou, uma era sobreposta à outra. Inscrevíamos, assim, as crianças perigosamente em uma história única.

Constatamos, deste modo, que as narrativas recorrentemente usadas nas avaliações da Educação Infantil procuram enquadrar os modos de ser da criança, como isto ou aquilo. Logo, o fato de compreendê-la como sendo de um modo, excluí a possibilidade de que ela seja, simultaneamente, de outro. Neste encaminhamento, quase nunca se trabalha nos relatórios com uma escrita em tensão, onde a criança seja, concomitantemente: isto; aquilo; um pouco mais e às vezes, a afirmação e/ou a negação de tudo aquilo que ela parece ser.

Nesta perspectiva, os relatórios de avaliação do desenvolvimento que produzimos sobre as crianças revelam um empobrecimento do que elas seriam ou são na interação com mundo, com seus pares e com os adultos que se encontram a sua volta. Isso, porque eles focam na tentativa de "capturar" linearmente os movimentos infantis. Produzindo um "congelamento" dos momentos vividos, tais que dizem pouco ou mesmo contradizem o dinamismo dos modos possíveis de ser criança no mundo em interação com diferentes contextos e sujeitos. 
Contudo, sabemos como afirmam os estudos no campo da Sociologia da Infância, que as crianças são um fenômeno social. Elas ressignificam e são coprodutoras de cultura através da interação com seus pares, os adultos e com as mídias presentes em seus contextos. Estudos como de Sarmento (2008); Corsaro (2011), Ferreira (2004) e Qvortrup (2011) nos possibilitam compreender a agencia, a atuação social infantil, nos fornecendo evidências de que elas não são sujeitos passivos, meros receptores de cultura. Mas, que possuem uma competência interpretativa e transcriadora (BENJAMIM, 2008) do mundo a sua volta.

Assim, esta multiplicidade dos modos de ser criança, que trazemos na discussão; esta que atravessa os desafios enfrentados, por Letícia e Celeste e também refletido por todos os profissionais da instituição, para a elaboração do relatório de desenvolvimento de Edson André, não deve ser compreendida como desvio de conduta moral e/ou de personalidade, discussão levantada no processo formativo. Trata-se da riqueza provocada por diferentes experiências interativas entre adultos e crianças.

\begin{abstract}
“Antes de tudo, a concepção de infância que nos move - aquela vista como capaz, competente, ativa, cidadã de pouca idade. Hoje temos inúmeros pesquisadores que escrevem sobre isso e esse é pressuposto básico para o nosso olhar. Com essas lentes, então, começo a discorrer sobre o fato de criarmos os espaços de narrativa com crianças variadas" (LEITE, 2008, p.123).
\end{abstract}

As considerações apontadas por Leite, sobre os modos de conceber a infância são relevantes, porque as experiências infantis quase nunca se aprisionam nas formas como nós as concebemos. Assim, compreender a criança como um ator social (SARMENTO, 2008) é também trabalhar com a compreensão de que elas estão experienciando, reinventando muitos modos de ser. Tanto aquele modo que os adultos esperam que elas representem, se enquadrem, como aqueles modos de ser criança, que elas próprias (re)inventam em respostas aos estímulos provocados pelo mundo.

Podemos entender que as concepções de infâncias são geradas, em um entre lugar (BHABHA, 1998): a) a ideia infância concebida e propostas pelos adultos e; b) a vivenciada pelas crianças, através de microsubversões e (re)invenções do que lhes é proposto pelos adultos. Nas relações tecidas neste entre lugar, temos o nascimento de uma concepção de infância ordinária (CERTEAU, 1994) diferente de todas as que por aqui passaram e todas as 
que estão por vir. É preciso muita proximidade das crianças para perceber as sutis diferenças que historicamente vai fazendo cada um de nós único.

Para além, deste movimento inicial do qual acabamos de refletir: a busca de uma verdade única, uma única forma de conceber a criança, presente no encaminhamento dos relatórios de avaliação do desenvolvimento delas. A discussão no grupo ganhou mais fôlego, polifonia e tensão, quando as profissionais da instituição foram provocadas a pensar sobre o modo como efetivamente somos, enquanto humanos, analisando os modos de relacionamentos que tecemos no dia a dia. As respostas construídas no processo formativo revelam um pouco das concepções de homem, de educação e de mundo, com que estas educadoras dialogam para construir suas intervenções pedagógicas.

As discussões apresentadas pelas educadoras do CEI sobre como podemos ser socialmente em uma determinada cultura, remetem-me a compreensão da sociedade como um aprisionamento do jeito de ser. Para algumas educadoras, o nosso jeito de ser precisa estar encaixado na forma que já está posta na sociedade e para outras, o nosso jeito de ser pode remodelar e/ou mesmo instituir novas formas de ser, inclusive pode-se ser multiforme.

Assim, se olhamos o sujeito infantil por um prisma moral rígido, como sugerido na discussão pelo primeiro grupo de profissionais, no diálogo formativo. Esse olhar requer ausência de mobilidade de contexto e o máximo de sacrifício para que o sujeito se enquadre no que está estabelecido como verdade, como forma correta de ser e estar no mundo. Nesta compreensão, muitos esforços e estratégias são investidos para que as crianças, sejam podadas, mutiladas no seu modo de ser, para serem aquilo que a sociedade espera que sejam. Se fossemos pensar em um modelo educacional para promover a educação de quem traz esta compreensão de homem e de mundo. Tal modelo provavelmente se assentaria em uma perspectiva autoritária. Sem qualquer base dialógica, já que aqueles que não se enquadram no modelo são considerados anormais. Portanto, se não cabem nos modelos sociais préestabelecidos devem sofrer intervenções para se tornarem o que se espera que sejam. Não se tornando podem sofrer exclusões.

A segunda ideia que algumas educadoras apresentaram na conversa, não abandona de tudo a concepção da necessidade de uma normalidade, de se seguir um padrão. O grupo apenas alarga a discussão no que concerne a não existência de um único jeito de ser, mas ainda trabalha com uma perspectiva moral. Neste caso, as crianças precisam aprender, o que cada contexto espera delas, enquanto comportamento aceitável. Se fossemos pensar em um 
modelo educacional para pensar neste modo de compreender o homem e sua relação com o mundo. Supomos que ainda não estaríamos em uma perspectiva dialética. Pois, apesar de se alargarem a compreensão de que somos um pouco mais múltiplos, a nossa multiplicidade está conduzida pelas formas impressas em cada um dos contextos sociais pelos quais circulamos. Assim, poderíamos supor que na escola temos tal comportamento, na instituição religiosa outro, no seio familiar outro... e assim vai. Como podemos perceber esta perspectiva não abandona a ideia de existência de um padrão a ser apreendido. Neste sentido ainda podem fazer-se presente a prática de intervenções muito autoritárias e violentas, apesar da ampliação das possibilidades de manifestação dos modos de ser e estar no mundo.

O último grupo é que do nosso ponto de vista traz uma complexidade maior, no que concerne aos modos de ser e estar no mundo, pensando na multiplicidade de papéis que um sujeito pode representar concomitantemente na sociedade. Pensar a educação, a partir desta leitura de mundo e de homem mais alargada/ aberta, revela-se para nós um desafio, uma vez que estamos acostumados a ter um olhar classificatório, linear, estático e/ou dicotômico. Portanto, empobrecido, sobre os modos como vimos buscando traduzir as crianças nos relatórios de avaliação. Nossa compreensão é de que o projeto de educação necessário para se pensar as intervenções pedagógicas destes sujeitos, sugerem, perspectivas que se revelam para nós como revolucionárias e emancipatórias. Uma vez que os sujeitos não apenas reconhecem e experimentam as formatações sociais encaminhadas para os modos possíveis de ser e estar no mundo. Mas, também são convocados a transgredi-las e/ou reinventa-las através das interações com os outros sujeitos.

Estas duas últimas perspectivas: a) tanto a que percebe que as crianças interagem de forma diferente em diferentes contextos sociais, por processo de adaptações e acomodações, e; b) quanto a que compreendem que as crianças recriam formas interativas em interação com os que estão a sua volta o tempo todo, reinventando o tempo todo os seus modos de ser no mundo. Ajudam-nos a ampliar nosso olhar, para melhor refletir sobre os encaminhamentos que tecemos nos relatórios de avaliação.

Especialmente, a última abordagem, compartilhada pelas educadoras, Vanessa Fernandes e Monique, provocou ao grupo a considerar a hipótese de que a questão não era que tivéssemos dois "Andrés" no agrupamento. Passamos a considerar que as experiências interativas entre: André, Letícia, os grupos de pares infantis e o ambiente e, entre André, Celeste, os grupos de pares infantis e o ambiente eram singulares. 
Então, cada um destes elementos: André, educadora, demais crianças da turma e do CEI, a organização do espaço e, tanto outros elementos/ variáveis que não mapeamos naquele momento, mas que sabíamos que se faziam presentes. Traduziam-se em equações que produziam resultados interpretativos diferenciados. Neste caso que trouxemos, as experiências sócio-afetivas e culturais entre as educadoras e o menino, não conseguiram produzir o mesmo resultado. $\mathrm{O}$ que não significa que uma delas estivesse mentindo sobre o desenvolvimento de André. De modo, que não temos um relatório verdadeiro e outro falso, temos duas leituras possíveis que nasceram de interações singulares. Mas, como pensar este encaminhamento com as famílias?

As famílias e suas leituras sobre as crianças: "comigo é assim, com irmão é assado, com a tia e avó é mimado, com o pai é um santo..."

Para as educadoras parecia que ia produzir muita tensão com as famílias a discussão sobre as muitas possibilidades de registro de uma mesma criança, sobre um mesmo período de desenvolvimento. Em especial se as versões deste desenvolvimento apresentassem elementos antagônicos. Apesar, do receio do grupo, defendi como gestora da instituição que levássemos a discussão, para uma reunião com as famílias, acreditando que pudéssemos aprender um pouco mais sobre as crianças.

E em uma reunião com as famílias, convidamos os presentes a refletir e a narrar experiências antagônicas que traduzissem um pouco de quem era aquela criança que estavam representando na reunião. Pedi que tentassem se lembrar de falas de parentes, vizinhos, colegas e outras crianças que se revelaram de algum modo surpresa sobre a compreensão que tinham daquela criança. Algo que alguém tivesse dito sobre a criança, que era, aparentemente, a negação e/ou um elemento surpresa sobre a criança a qual achavam tanto conhecer.

Diante da proposta, muitas conversas paralelas apareceram e em um primeiro momento, o que mais pude escutar delas foi riso e comentários de que aquilo era o que mais acontecia. E, sem precisar de todo tempo para reflexão, logo um adulto que representava uma criança disse:

A Luna apronta todas aqui e em casa. Mas aqui eu sei que ela apronta mais e aprende mais, porque em casa só tem TV para ela interagir. Chego tarde porque trabalho de enfermeira e a vejo pouco. Vejo nos fins de semana 
dividido com pai. Mas com o pai ela é uma lady. Ele diz que eu e a creche pegamos pesado no modo como descrevemos a Luna nos relatórios de avaliação. Ele acha ela muito parada pra tudo, Dá pra acreditar?! (Deisy Hang - 27 anos - mãe de Luna de 5 anos)

O Andrezinho comigo é ativo, fala, corre e pede as coisas. Até bate no irmão, tenho que zangar com ele. Ele quer tudo pra ele. Adora dançar com os Backyardigans $^{\text {iv }}$ da televisão. Com o pai, ele quase não fala. Ele fica quietinho, espera com calma o pai atende-lo, comigo fica gritando. Meu marido não acredita quando conto que ele bate no irmão, por ele ser menor e por acha-lo calminho. Lá na igreja, ele não fala nada com ninguém e só fica no meu colo, as pessoas acham que ele não sabe andar. Eu pensava que ele não gostava da igreja e às vezes deixava ele com minha mãe. Mas, ele não gostou. Ele pede para ir, dá pra entender?! Ele comigo é assim, com o irmão é assado, com a tia e a avó é mimado, com o pai é um santo. (Ana Lúcia da Silva - 37 anos - mãe de Edson André de 2 anos)

Eu muitas vezes discordo do que a tia Marcia fala do Felipe no registro de avaliação. Mas eu sei que ninguém é o mesmo em todos os lugares. Mas, às vezes, nas conversas com ela no portão, eu me assusto com os comentários que ela faz. Porque eu não reconheço o Felipe que ela descreve. Mas eu sei que ele aqui é diferente, às vezes, chego cedo faço hora ali na escadaria e escuto a euforia dele com os amiguinhos, também escuto as conversas no ponto de ônibus. Mas em casa e nos outros lugares que eu vou o Felipe é outro. Ele é superdifícil de interagir com outras pessoas. Mas aqui é meio bicho solto, sabe?.

(Vânia Antunes - 31 anos - mãe de Felipe de 4 anos)

A conversa com as famílias confirmou a ideia de que as crianças eram múltiplas. Por vezes, contraditórias até mesmo irreconhecíveis no contexto escolar, como revela a narrativa da mãe de Felipe. O encaminhamento da discussão na reunião com as famílias, revelou-se uma surpresa para os profissionais da instituição, que estavam trabalhando com a hipótese de que as famílias negariam que as crianças pudessem revelar múltiplas versões de si mesmas, dependendo dos contextos e/ou dos sujeitos com os quais interagem.

Claro que isso não apaga as tensões cotidianas entre educadoras e famílias, nas conversas sobre os modos de cada ser criança, no diálogo cotidiano que tecem para reconhecê-la. A fala de Vânia, mãe de Felipe, anuncia um pouco de seus conflitos no caminho de reconhecimento que buscava trilhar para perceber as interações tecidas pelo menino no CEI. Para ela, o Felipe do CEI era um desconhecido, considerando o que ela observava do menino em outros contextos nos quais ela o acompanhava. Sua fala traz, inicialmente, um fundo de surpresa e mostra que a conformação dela com estas nuances diferentes na interpretação dos modos de ser criança do Felipe foi se acomodando, na medida em que ela 
mesma passou investir seu tempo para observar, ainda que indiretamente, as interações do menino com seus pares e os adultos na creche.

O diálogo com as famílias e o processo formativo que articulamos no interior da instituição, para entender as divergências que temos diariamente nos modos de conceber as crianças; convida-nos a rever esta necessidade que temos de conceber os registros do desenvolvimento das crianças, como um instrumento generalizante dos seus múltiplos modos de ser e estar no mundo.

É importante, ainda, não escamotear as capacidades de interpretação dos actores-crianças - que conseguem inteligentemente jogar e tirar partido das ambiguidades, incoerências e contradições - e considerar outras concepções de adultos, não unicamente repressivo mas também restitutivo ou cooperativo. (FERREIRA, 2004, p. 101).

Os estudos de Ferreira nos ajudam a reconhecer que as crianças não são ingênuas. Elas aprendem a ler a realidade e os sujeitos criticamente, por isso não interagem da mesma forma com todos. Elas jogam com as interações sociais. Diante de toda a complexidade que envolve compreender os recém-chegados (ARENDT, 2007) ao mundo: sujeitos que realizam leituras de mundo e as articulam nos modos como tecem o convívio social. É urgente pensarmos instrumentos de registros de desenvolvimento que alberguem as múltiplas formas possíveis, inclusive, as formas contraditórias experimentadas pelas crianças como caminhos de interação, de (re)conhecimento e de (re)invenções de suas condições de existência em diferentes contextos e com diferentes sujeitos.

Nossa compreensão é de que esta necessidade de padronização e de produzir generalizações sobre as crianças é uma necessidade muito mais nossa, enquanto, profissionais da educação do que das famílias. Pois, as famílias do CEI Carolina Amorim, revelam compreender que as crianças se fazem hibridas (BHABHA, 1998) nas interações que tecem. Elas ressignificam e reelaboram suas experiências interativas, o que impossibilita uma afirmação generalizante que as enquadre como sendo de um modo ou de outro.

Cada criança por definição é hibrida, sendo isto, aquilo, um pouco mais e uma surpresa constante. Elas constantemente estão se reelaborando a partir dos contextos e dos sujeitos com os quais interagem. Esta reelaboração é sempre única porque é produzida pela ação da cultura interpretativa (CORSARO, 2011) produzida pelas crianças. 


\section{Considerações Finais}

$\mathrm{O}$ processo formativo que o texto apresentou nos convocou em alguns momentos a refletir como as concepções de infância, de criança e de educação com que vínhamos trabalhando na instituição, ainda não davam conta de dialogar com a complexidade dos muitos modos de ser criança. Ajudando-nos a reconhecer a contradição do encaminhamento de alguns passos de nosso trabalho pedagógico, em especial o processo de produção dos registros descritivos de desenvolvimento infantil, que suprimia a possibilidade de existência de uma polifonia interpretativa de vozes sobre as crianças.

A discussão neste sentido fez-nos enfrentar algumas de nossas contradições epistêmicas, diante dos desafios que enfrentávamos: a) o desafio de ter as crianças como protagonistas do processo educativo; b) o diálogo com uma concepção de educação que respeitasse as diferenças entre as crianças, e; c) o diálogo constante com as famílias no encaminhamento das questões pedagógicas da instituição.

$\mathrm{Na}$ reflexão feita diante dos desafios que nos colocávamos profissionalmente, percebemos que embora nosso esforço fosse legítimo em relação aquilo que havíamos estabelecido. Ainda nos encontrávamos distantes do proposto, considerando as reflexões que tecemos em diálogo com as provocações desencadeadas pela experiência compartilhada por Letícia e Celeste.

O modo como organizávamos o instrumento de registro de desenvolvimento das crianças, apagava o hibridismo de seus modos de ser e interagir com os sujeitos e, os contextos a sua volta. Isso acontecia porque centrávamos em uma perspectiva de avaliação universal.

A perspectiva de avaliação adotada para registrar o desenvolvimento das crianças, denunciava o quanto nossa concepção de educação não favorecia o protagonismo das crianças. Ao contrário, a ênfase do olhar adultrocêntrico, chegava até mesmo compreender como legítimo apagar as experiências que não correspondiam as nossas leituras.

Também nos foi revelador como as famílias podem nos ajudar a apagar problemas ilusórios que inventamos para nós mesmos. As famílias e suas contribuições nas reflexões que tecemos não compactuavam com as generalizações que fazíamos das crianças nos relatórios. Elas nos ajudavam a ampliar as leituras que fazíamos sobre as crianças e refutavam com isso 
a hipótese de que elas eram as que mais necessitavam de pensar relatórios simplistas sobre as crianças. Todos os presentes, naquela reunião, revelaram a compreensão de que as crianças são hibridas e que apresentam muitos modos de ser dependendo dos contextos e dos sujeitos com que se encontram em interação.

Neste sentido, o texto trouxe uma discussão importante sobre as questões formativas que o grupo de profissionais do CEI Carolina Amorim vivenciou na reflexão sobre reelaboração e a transformação da prática pedagógica.

\section{REFERÊNCIAS}

ADICHIE, Chimamanda. O perigo de uma história única. Vídeo publicado em 2009. Disponível em:

<https://www.ted.com/talks/chimamanda_adichie_the_danger_of_a_single_story/transcript?la nguage=pt-br $>$. Acesso em: 31 mai. 2016.

ALVES, Nilda. Decifrando o pergaminho: o cotidiano das escolas nas lógicas das redes cotidianas. In: OLIVEIRA, Inês Barbosa de; ALVES, Nilda (Org.). Pesquisa no/do cotidiano das escolas: sobre redes de saberes. Rio de Janeiro: DP\&A, 2001. p.13-37.

ALVES, Nilda; GARCIA, Regina Leite (orgs.). A Invenção da Escola a cada dia. Rio de Janeiro: DP\&A, 2000.

ARENDT, Hannah. A condição humana. 10 ed. Rio de Janeiro: Forense Universitária, 2007.

BENJAMIN, Walter. A Tarefa do Tradutor. Belo Horizonte: Fale/UFMG, 2008.

BHABHA, Homi K. O local da cultura. Belo Horizonte: UFMG, 1998.

CARREIRO, Heloisa Josiele Santos Carreiro. Rotinas arquitetadas e cotidianos vividos: tensões e possibilidades na Educação Infantil. Tese de Doutorado - Universidade Federal Fluminense, Faculdade de Educação, 2013.

CERTEAU, Michel de. A invenção do cotidiano: 1 . Artes de fazer. Petrópolis - Rio de Janeiro: Vozes, 1994.

CORSARO, William. Sociologia da Infância. 2 2 Edição. Porto Alegre: Artmed, 2011.

ESTEBAN, Maria Teresa. Avaliação: uma prática em busca de novos sentidos. Rio de Janeiro: DP\&A, 2000.

FERREIRA, Manuela. A gente gosta é de brincar com os outros meninos! Relações sociais entre crianças num Jardim de Infância. Porto: Afrontamento, 2004. 
GARCIA, Regina Leite. A professora investigadora e o processo de produção de novos conhecimentos sobre a prática pedagógica. In.: Anais do $9^{\circ}$ ENDIPE. Águas de Lindóia, SP: 1998.

GINZBURG, C. Mitos, emblemas e sinais. São Paulo: Cia das Letras, 1989.

LEITE, Maria Isabel. Espaços de narrativa - onde o eu o outro marcam encontro. In.: CRUZ, Silvia Helena Vieira. A criança fala - a escuta de crianças em pesquisas São Paulo: Cortez, 2008. p. 118-140.

QVORTRUP, Jens. Apresentação - Nove teses sobre a infância como um fenômeno social. Revista Pro-Posições, Campinas, v. 22, n. 1 (64), p. 199-211, jan./abr. 2011.

SARMENTO, Manoel Jacinto. Estudos da Infância - Educação e Práticas Sociais. Petrópolis, RJ: Vozes, 2008.

\footnotetext{
i Doutora em Educação, Professora Adjunta da UERJ-FFP.

iiii Por lentes chamamos neste texto a seguinte estratégia metodológica adotada pelos profissionais: um mês antes de fechar os relatórios junto com a gestão, os profissionais selecionavam pontos sobre os quais os relatórios seriam encaminhados. Esses pontos de observação eram por nós nomeados como lentes. As lentes ajudavam-nos a ter um relatório diferenciado em cada bimestre. Pois, para cada bimestre tínhamos lentes diferentes, enriquecendo os pontos de observação que compartilhávamos com as famílias das crianças.

iii Há instituições da rede em que os diretores realizam sozinhos os relatórios de todas as crianças. A supervisora de nossa instituição autorizou este encaminhamento metodológico. Contudo, caso alguma educadora não quisesse participar deste encaminhamento, ela poderia recursar-se a fazê-lo. Já que o município entende que a atribuição da produção de relatórios é específica do professor.

iv Programa com personagens infantis na televisão. Trata-se de um seriado infantil em que os personagens compartilham suas aventuras e muitas canções.
} 